\title{
Parental infections disrupt clustered genes encoding related functions required for nervous system development in newborns
}

\author{
Bernard Friedenson \\ Department of Biochemistry and Molecular Genetics \\ College of Medicine \\ University of Illinois Chicago \\ Chicago, IL \\ molmeddoc@yahoo.com
}




\section{Abstract}

The purpose of this study was to understand the role of infection in the origin of chromosomal anomalies linked to neurodevelopmental disorders. In children with disorders in the development of their nervous systems, chromosome anomalies known to cause these disorders were compared to viruses and bacteria including known teratogens. Results support the explanation that parental infections disrupt elaborate multi-system gene coordination needed for neurodevelopment. Genes essential for neurons, lymphatic drainage, immunity, circulation, angiogenesis, cell barriers, structure, and chromatin activity were all found close together in polyfunctional clusters that were deleted in neurodevelopmental disorders. These deletions account for immune, circulatory, and structural deficits that accompany neurologic deficits. In deleted gene clusters, specific and repetitive human DNA matched infections and passed rigorous artifact tests. In some patients, epigenetic driver mutations were found and may be functionally equivalent to deleting a cluster or changing topologic chromatin interactions because they change access to large chromosome segments. In three families, deleted DNA sequences were associated with intellectual deficits and were not included in any database of genomic variants. These sequences were thousands of bp and unequivocally matched foreign DNAs. Analogous homologies were also found in chromosome anomalies of a recurrent neurodevelopmental disorder. Viral and bacterial DNAs that match repetitive or specific human DNA segments are thus proposed to interfere with highly active break repair during meiosis; sometimes delete polyfunctional clusters, and disable epigenetic drivers. Mis-repaired gametes produce zygotes containing rare chromosome anomalies which cause neurologic disorders and accompanying nonneurologic signs. Neurodevelopmental disorders may be examples of assault on the human genome by foreign DNA with some infections more likely tolerated because they resemble human DNA segments. Further tests of this model await new technology.

Keywords: I; genome 2; epigenetics 3; neurodevelopmental disorders; 4; chromosome anomalies; 5; retrotransposon; 6; chromosome rearrangement; 7; neurologic disease; 8; birth defects; 9; development 10; infection 


\section{Graphic Abstract}

Some infection DNA can integrate into human DNA (e.g. retroviruses) and many bacterial and viral DNAs can interfere with meiosis or mitosis because of homologies to sections of human DNA (green stripes below). These events can interfere with coordinated neurodevelopment by deleting essential gene clusters, inactivating epigenetic controllers and disrupting topologic chromatin associations.

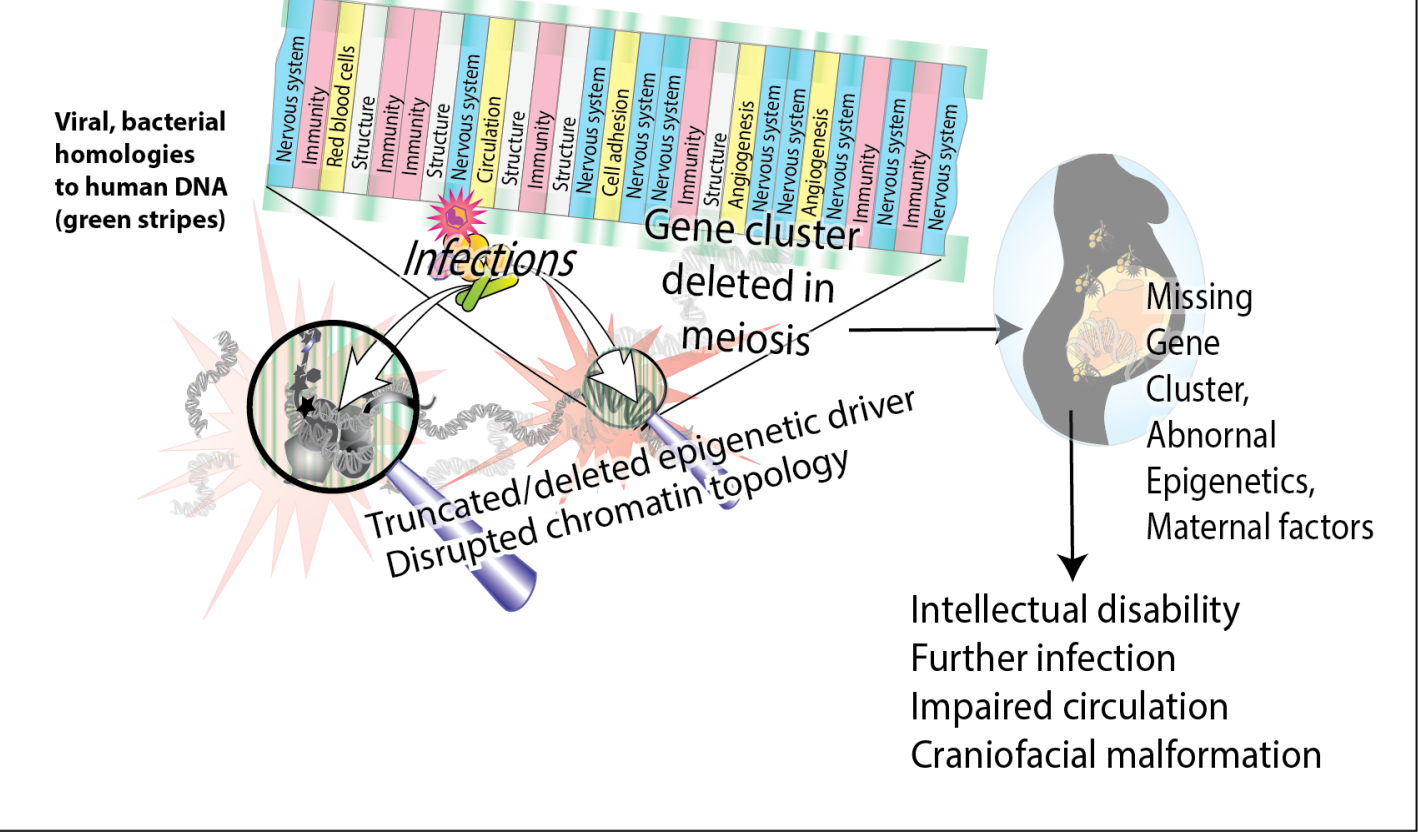

\section{Introduction}

An approach to preventing neurodevelopmental disorders is to gain better understanding of how neurodevelopment is coordinated and then to identify environmental and genomic factors that disrupt it. The development of the nervous system requires tight regulation and coordination of multiple functions essential to protect and nourish neurons. As the nervous system develops, the immune system, the circulatory system, cranial and skeletal systems must all undergo synchronized and coordinated development. Neurodevelopmental disorders follow the disruption of this coordination.

A significant advance in genome sequence level resolution of balanced cytogenetic abnormalities greatly improves the ability to document changes in regulation and dosage for genes critical to the function of the neurologic system. Based on DNA sequence analyses, some chromosome rearrangements have been identified as causing individual congenital disorders because they disrupt genes essential for normal development ${ }^{1-3}$. 
There is poor understanding and no effective treatment for many of these overwhelming abnormalities. Signs and symptoms include autism, microcephaly, macrocephaly, behavioral problems, intellectual disability, tantrums, seizures, respiratory problems, spasticity, heart problems, hearing loss, and hallucinations '. Because such abnormalities do not correlate well with prognosis, genetic counseling is difficult and uncertain ${ }^{3}$.

In congenital neurologic disease, inheritance is usually autosomal dominant and the same chromosomal abnormalities occur in every cell. The genetic events that lead to most neurodevelopmental disorders are not understood ${ }^{4}$ but several maternal infections and other lifestyle factors are known to interfere. The present work implicates foreign DNA from infections as a source of the chromosome anomalies that cause birth defects. Infections replicate within the CNS by taking advantage of immune deficiencies such as those traced back to deficient microRNA production ${ }^{5}$ or other gene losses. Disseminated infections can then interfere with the highly active DNA break repair process required during meiosis. Gametes with mis-repaired DNA then cause chromosome anomalies in the zygote. The generation of gametes by meiosis is the most active period of recombination. Double strand breaks initiate meiotic recombination and hundreds of double strand breaks occur ${ }^{6}$. In contrast to oocytes, meiotic recombination in sperm cells occurs continuously after puberty.

The exact DNA sequences of known pathogenic rearrangements in unique, familial and recurrent congenital disorders ${ }^{1-3}$ makes it possible to test for the involvement of microbial DNA. Even rare and unique developmental disorders can be screened for homology to infections in the context of altered chromatin structure affecting the immune system, the circulatory system, the formation of the brain-circulation barriers and bone development. This screening may assist counseling, diagnosis, prevention, and early intervention.

The present results show that DNAs in some congenital neurodevelopmental disorders closely matches DNA in multiple infections. The matches extend over long linear stretches of human DNA and often include repetitive human DNA sequences. Neurodevelopmental disorders are proposed to begin when parental infections cause insertions or interfere with meiosis at both repetitive and unique human DNA sequences. The affected sequences are shown to exist as linear clusters of genes closely 
spaced in two dimensions. Interference from infection can also delete or damage human gene clusters and epigenetic regulators that coordinate neurodevelopment. This microbial interference accounts for immune, circulatory, and structural deficits that accompany neurologic deficits. Congenital neurodevelopmental disorders are thus viewed as resulting from an assault on human DNA by microorganisms and an example of the selection of infecting microorganisms based on their similarity to host DNA.

Generating a viable model based on these results may spur the development of methods for identifying contributions from infections in intractable rare disorders that are not now available. Convergent arguments from testing predictions based on any proposed model might lessen effects of limitations in currently available technology.

\section{Materials and Methods}

Data Sources. DNA sequences from acquired congenital disorders were from published whole genome sequences at chromosome breakpoints and rearrangement sites ${ }^{1-3}$. Comparison to multiple databases of microbial sequences determined whether there was significant human homology. Emphasis was on cases with strong evidence that a particular human chromosome rearrangement was pathologic for the congenital disorder.

Testing for microbial sequences. Hundreds of different private rearrangements in patients with different acquired congenital disorders were tested for homology ${ }^{7}$ against nonhuman sequences from microorganisms known to infect humans as follows: Viruses (taxid: 10239), and retroviruses including HIV-I (taxid:I 1676), human endogenous retroviruses (Taxids:456 I7, 87786, I I745, I 3520I, I66I22, 228277and 35268); bacteria (taxid:2); Mycobacteria (taxid:85007); and chlamydias (taxid:5I29I)

Because homologies represent interspecies similarities, "Discontinuous Megablast" was used. Significant homology (indicated by homology score) occurs when microbial and human DNA sequences have more similarity than expected by chance (E value $<=e-10){ }^{8}$. Confirmation of microorganism homologies was done by testing multiple variants of complete microorganism genomes against human genomes.

Various literature analyses have placed Alu repeats into 8 subfamilies having consensus sequences (GenBank; accession numbers UI4567 - UI4574). Microbial sequences were independently compared to all 8 consensus Alu sequences and to 442 individual AluY sequences. 
Chromosome localizations. The positions of microbial homologies in human chromosomes were determined using BLAT or BLAST. Comparisons were also made to cDNAs based on 107,186 Reference Sequence (RefSeq) RNAs derived from the genome sequence with varying levels of transcript or protein homology support. Tests for contamination by vector sequences in these non-templated sequences were also carried out with the BLAST program. Inserted sequences were also compared to Mus musculus GRCM38.p4 [GCF_000001635.24] chromosomes plus unplaced and unlocalized scaffolds (reference assembly in Annotation Release 106). Homology of inserted sequences to each other was tested using the Needleman and Wunsch algorithm.

\section{Results}

\section{Interdependent functions are clustered together on the same chromosome segment.}

The nervous system shows a close relationship to structures essential for immunity, circulation, cell barriers and protective enclosures. In chromosome segments deleted in neurologic disorders, genes essential for all these functions must develop in concert. Genes for these related functions are located close to each other on the same linear segment of a chromosome (Fig. I). Deletions at $4 q 34$ in patient DGAPI6I and at I9qI2-13.1I in patient DGAPI 25 are shown in Fig. I, as examples that are representative of the other large chromosomal deletions. The genes within each deletion in each of four categories tested are color coded in the figure. Deletion of these clustered arrangements has been correlated with serious neurodevelopmental disorders'. Alternatively-spliced forms of the same gene may encode for different functions that must be synchronized and coordinated among diverse cells. Multiple functions in different cell types are commonly found. Hormonal signaling represents a major control mechanism?. 


\begin{tabular}{|c|c|}
\hline \multicolumn{2}{|c|}{ Chromosome 4q34 gene cluster, deleted in patient DGAP161 } \\
\hline \multirow{4}{*}{ HMGB2 } & Controls neural stem cell proliferation \\
\hline & $\begin{array}{l}\text { V(D)J recombination DNA RNA sensor in Innate immune response to nucleic acids. } \\
\text { Chemokine. Anti-microbial }\end{array}$ \\
\hline & Red blood cell differentiation \\
\hline & Connective tissue differentiation \\
\hline SAP30 & $\begin{array}{l}\text { Hematopoiesis, anti-inflammatory response to glucocorticoids. } \\
\text { Hypoxia response }\end{array}$ \\
\hline \multirow{2}{*}{ SCRG1 } & Autophagy, Anti-inflammatory, chemotaxis for immune system cells, prion response \\
\hline & Bone differentiation from stem cells \\
\hline \multirow{3}{*}{ HAND2 } & Noradrenergic properties of neurons, controls neuroblast multiplication \\
\hline & Development of circulation, cardiac development \\
\hline & Craniofacial skeleton \\
\hline \multirow{2}{*}{ HPGD } & Pro-inflammatory gene \\
\hline & Bone structure and connective tissue \\
\hline GLRA3 & $\begin{array}{l}\text { Tonic and agonist induced currents in forebrain, auditory nerve activity, } \\
\text { brain development, vision }\end{array}$ \\
\hline ADAM29 & Cell adhesion and membrane structure \\
\hline GPM6A & $\begin{array}{l}\text { Signaling in neuron lipid rafts. Dendritic spine and synapse formation. } \\
\text { Candidate causal gene for schizophrenia }\end{array}$ \\
\hline WDR17 & Retinal development \\
\hline \multirow{2}{*}{ SPATA4 } & Apoptosis inhibitor \\
\hline & Osteoblast differentiation \\
\hline ASB5 & Vascular remodeling in embryogenesis, artery development \\
\hline SPCS3 & Preprohormone convertase affects pituitary hormone ghrelin \\
\hline \multirow{2}{*}{ VEGFC } & Neural stem cell activation \\
\hline & Formation of lymphatics, Endothelial cell migration, Circulation \\
\hline \multirow{2}{*}{ NEIL3 } & Induces neurogenesis \\
\hline & B-cell expansion in germinal center, prevention of autoimmunity \\
\hline \multirow{2}{*}{ AGA } & Thalamus structure \\
\hline & Aspartylglucosaminidase, lysosomal hydrolase, joint inflammation \\
\hline TENM & Development in nervous system Synapse organization \\
\hline
\end{tabular}

\begin{tabular}{|c|c|}
\hline \multicolumn{2}{|c|}{ Chromosome 19q12-q13.11 gene cluster deleted patient DGAP125 } \\
\hline POP4 & $\begin{array}{l}\text { Ribosomal RNA processing } \\
\text { Bone density }\end{array}$ \\
\hline \multirow{2}{*}{ C19orf12 } & Brain iron accumulation \\
\hline & Oxidative stress response \\
\hline \multirow{2}{*}{ CCNE1 } & Loss accelerates precursor differentiation, remyelination in CNS \\
\hline & Mediates hematopoiesis, inactivated in HN-1 infection \\
\hline URI1 & Chaperone assembly of protein complexes, control DNA damage through apoptosis \\
\hline TSHZ3 & $\begin{array}{l}\text { Development of neurons essential for breathing } \\
\text { Smooth muscle cell differentiation } \\
\text { Protects intervertebral discs }\end{array}$ \\
\hline DPY19L3 & Neurodevelopment mannosyl transferase enhances Wnt signaling \\
\hline PDCD5 & Immune regulation, programmed cell death, regulated by NFKB, active in brain \\
\hline ANKRD27 & Endosomal traffic underlies dendrite outgrowth of neural tube derived melanocytes \\
\hline NUDT19 & Brain acetyl coenzyme A levels Energy metabolism, mRNA stability \\
\hline RGS9BP & Photoreceptor function GTP signaling \\
\hline TDRD12 & Retrotransposon repression \\
\hline CEP89 & Mitochondrial metabolism, neuronal and cognitive function \\
\hline RHPN2 & $\begin{array}{l}\text { Targeted by EBV in lymphomas } \\
\text { Transformation of neural stem cells into bone, cartilage, and muscle }\end{array}$ \\
\hline GPATCH1 & Bone density \\
\hline \multirow{2}{*}{ LRP3 } & Synapse reorganization and selection during learning \\
\hline & $\begin{array}{l}\text { LDL receptor role in macrophage mediated inflammation and cholesterol processing } \\
\text { Promotes differentiation into bone producing cells, turns off fat cell production }\end{array}$ \\
\hline SLC7A10 & Synaptic plasticity, NMDAR activation, inhibitory transmission, serine glycine transport \\
\hline \multirow{3}{*}{ CEBPA } & Prolactin transcription, cortical dendrite differentiation \\
\hline & Granulocyte-monocyte progenitors, lineage specification, response to brain injury, \\
\hline & Osteoclast lineage commitment, chondrocyte proliferation and differentiation \\
\hline CEBPG & Anti-Virus responses, regulates inflammation \\
\hline \multirow{2}{*}{ PEPD } & Prolidase, A major regulator of interferon type 1 responses, cell injury signal \\
\hline & Angiogenesis, pia mater membrane integrity \\
\hline CHST8 & $\begin{array}{l}\text { Sulfotransferase, Affects prion infection } \\
\text { keratan sulfate structure, macular dystrophy }\end{array}$ \\
\hline KCTD15 & $\begin{array}{l}\text { Inhibits neural crest formation. Slows development and differentiation } \\
\text { into a variety of derivatives. Neural control of body mass index }\end{array}$ \\
\hline LSM14A & Senses viral RNA or DNA to produce Interferon beta, Active in early viral infection. \\
\hline GPI & $\begin{array}{l}\text { Promotes survival of skeletal motor and sensory neurons } \\
\text { Lymphokine that induces immunoglobulin secretion } \\
\text { Brain angiogenesis, response to hypoxia }\end{array}$ \\
\hline PDCD2L & Regulation of apoptosis \\
\hline UBA2 & Silences provirus in embryonic stem cells \\
\hline WTIP & Actinomyosin contractility in neural tube closing, body organization, cilia growth \\
\hline SCN1B & $\begin{array}{l}\text { Transmission of electrical impulses in nerve and muscle cells } \\
\text { Heart muscle function }\end{array}$ \\
\hline
\end{tabular}

Fig. 1. Close relationships between the nervous system and other essential developmental functions. Genes for multiple interdependent systems appear in clusters on the same chromosomes. Nervous system genes are near genes essential for the immune system, connections to lymphatic circulation, ability to form tight junctions, structural enclosures and chromatin control. Clusters of genes encoding these and other interdependent functions on chromosome segments are deleted in private neurodevelopmental disorders. These losses increase susceptibility to infections which are homologous to long stretches of human DNA. In the two examples shown, genes are listed in the order they occur on two typical chromosome deletions. Functions are to the right of the gene symbol. Blue genes are associated with the nervous system, pink with the immune system. Yellow genes have functions associated with angiogenesis, lymphangiogenesis or cell barriers. Genes for development of essential bone structure or connective tissues needed to protect and house the nervous system are light grey. Genes colored purple code for general functions required by all cells. The same gene may function differently in different cellular locations. 


\section{Many deleted gene clusters include long stretches of DNA strongly related to} infections.

To investigate the chromosomal segment deletions that cause neurodevelopmental disorders, homologies to infection were tested in sequences within and flanking deleted clusters. Strong homologies to infections were interspersed. To demonstrate the extent of these relationships, deleted $4 q 34$ chromosome segment (Patient DGAPI6I ') was tested for homology to microbes in $200 \mathrm{~kb}$ chunks. Fig. 2 shows that stretches of homology to microorganisms are distributed throughout chromosome 4q34. Only 10 homologous microbes are shown for each $200 \mathrm{~kb}$ division, but there are up to hundreds, giving a total of many thousands of potentially homologous microorganisms throughout the $4 \mathrm{q} 34$ deletion.

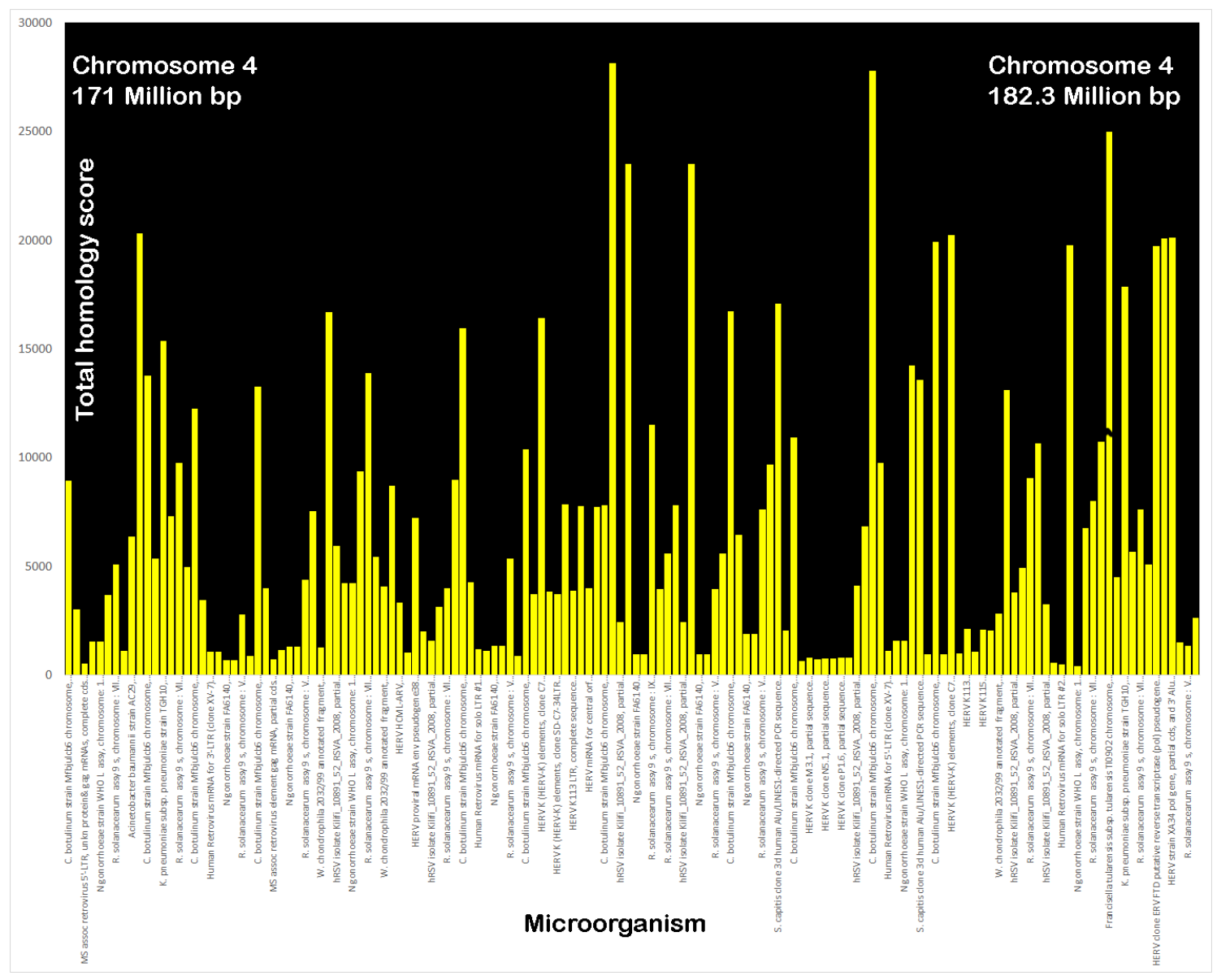

Fig. 2. Example of total homologies to microbial sequences dispersed throughout $4 q 34$ deleted chromosome segment in patient DGAP161. The top 10 homologies are shown for each 200,000 bp segment and are listed within each of these 57 segments in order of their scores. The $Y$ axis plots the total homology scores and the $x$ axis lists the individual microorganism. The mean E value was $5.3 e-90$ (range 0.0 to 1e-87). F. tularensis had values of 33,368 and 79,059 which were truncated at 25000 to show more detail for the other microbial matches. 
A deeper analysis of the functions of genes within deleted chromosome segments predicts a predisposition to infection and correlates with symptoms of the developmental disorder. For example, deletion of chromosome 19q/2-q/3.1 I occurs in patient DGAPI25 (Fig. I). The deletion causes deficits in silencing provirus, repressing retrotransposons, responding to viruses, specifying immune cell lineages, and regulating apoptosis. The deleted I9q |2-q 3 . I I band in patient DGAPI 25 had 76 matches to clostridium botulinum strain Mfbjuicb6. Many of these matches extended over 2800 bp at $72-73 \%$ homology $(E=0.0)$. There were also strong matches to Waddlia chondrophila and N. gonorrhoeae. Other shorter chromosomal anomalies are present in patient DGAPI25. Stealth and HIV-I teratogens and multiple other infections are homologous to these shorter anomalies (Fig. 3).

The large deletion in $19 q / 2-q|3.1|$ not only makes patient DGAPI 25 especially susceptible to infections but also deletes coordinated genes that control breathing, synapse organization and plasticity, neural crest formation, transmission of nerve impulses; development of brain circulation; and production of connective tissue and bone. Other chromosome deletions with clustered genes have deficits in neuronal accessory functions like those in DGAPI 25.

\section{Microbial DNA homologies in areas around a mutated epigenetic driver gene.}

Gene changes identified as underlying phenotypic drivers of congenital neurologic diseases ' were tested against published evidence for their ability to act as epigenetic regulators and effectors of functions like those found in the chromosomal deletions. Table I shows that most pathogenic driver genes are epigenetic regulators.

Fig. 3 graphically relates DNA sequences in all viruses and bacteria in the NCBI database to DNA sequences around breakage sites based on outstanding data published by the study of Redin and colleagues '. There may also be cryptic rearrangements elsewhere 2,3,10. The figure shows wide differences in the total homology scores of microbes vs. humans in individual disorders. Patient DGAPI54 has total homology scores of well over 50,000 while other patients (DGAPI42, 172, and I73) are well below 1000. 


\section{Pathogenic driver gene mutations are roughly equivalent to large chromosome deletions}

Because most identified driver genes of neurodevelopmental disorders ' are epigenetic regulators or effectors (Table I), the functions they control in individual patients and in families with members affected by neurodevelopmental disorders 3 were compared to genes in pathogenic chromosomal deletions. Like clustered chromosomal deletions, virtually all pathogenic driver genes have strong effects on the immune system, angiogenesis, circulation and craniofacial development. Fig. 4 summarizes how the functions of damaged epigenetic drivers are distributed.

Table I Epigenetic functions of mutated and deleted genes in neurodevelopmental disorders relate neurologic deficits to deficits in the immune system, the circulatory system and structural genes.

\begin{tabular}{|c|c|c|c|c|c|}
\hline Patient & $\begin{array}{l}\text { Proposed primary phenotypic drivers of anomaly or } \\
\text { disrupted genes. Genes in bold type are related to } \\
\text { epigenetic control }\end{array}$ & $\begin{array}{l}\text { Genes with pathogenic } \\
\text { neurologic mutation } " 1 \\
\text { associated with nervous } \\
\text { system function }\end{array}$ & $\begin{array}{l}\text { Genes deleted or } \\
\text { mutated linked to } \\
\text { immunity, } \\
\text { infection }\end{array}$ & $\begin{array}{l}\text { Genes deleted or } \\
\text { mutated with } \\
\text { linked to } \\
\text { circulation and } \\
\text { blood brain barrier }\end{array}$ & $\begin{array}{l}\text { Genes deleted or } \\
\text { mutated linked to } \\
\text { bone, structural } \\
\text { requirements }\end{array}$ \\
\hline DGAP002 & $\begin{array}{l}|4 q| 2-q 2|.| \text { deleted. FOXAI in the deletion mediates } \\
\text { chromatin remodeling }\end{array}$ & NOVAI, AKAP6 & $\begin{array}{l}\text { Fox GI, NFKBIA, } \\
\text { NKX2, BAZIA, } \\
\text { FoxAI }\end{array}$ & FoxAl & FoxAl \\
\hline DGAPOII & $\begin{array}{l}\text { FGFRI Receptor for gene that regulates chromatin } \\
\text { organization during development }\end{array}$ & FGFRI & FGFRI & FGFRI & FGFRI \\
\hline DGAPOI 2 & $\begin{array}{l}\text { PHF2 IA, chromatin regulator disrupted at breakpoint, } \\
\text { encodes part of histone deacetylase complex }\end{array}$ & $\begin{array}{l}\text { Encodes BHC80, BRAF35 } \\
\text { in histone deacetylase } \\
\text { complex. }\end{array}$ & $\begin{array}{l}\text { Histone } \\
\text { deacetylase }\end{array}$ & $\begin{array}{l}\text { Histone } \\
\text { deacetylase. }\end{array}$ & Not found \\
\hline DGAP093 & $\begin{array}{l}\text { CDKL5 gene disrupted at breakpoint, phosphorylates HDAC4 } \\
\text { histone deacetylase causing cytoplasmic retention }{ }^{12} \text {. }\end{array}$ & $\begin{array}{l}\text { CDKL5 Mediates MECP2 } \\
\text { phosphorylation. }\end{array}$ & CDKL5 & CDKL5 & Not found \\
\hline DGAP096 & $\begin{array}{l}\text { WAC at breakpoint, disrupted by translocation regulates } \\
\text { histone ubiquitination }\end{array}$ & WAC. & WAC & WAC & Not found \\
\hline DGAP099 & $\begin{array}{l}\text { ZBTB20 binds to genes that control chromatin architecture } \\
\text { including MEF2c and SAT2b }\end{array}$ & ZBTB20 & ZBTB20 & ZBTB20 & ZBTB20 \\
\hline DGAPI00 & $\begin{array}{l}\text { KDM6 Histone Demethylase and Epigenetic switch to specify } \\
\text { stem cell fate } 13\end{array}$ & KDM6A & KDM6A & KDM6A & KDM6A \\
\hline DGAPII 2 & $\begin{array}{l}|2 \mathrm{p}| 2 . \mathrm{I}-\mathrm{p} \mid \mathrm{I} .22 \text { deleted. SOX5, a histone demethylase at } \\
\text { breakpoint is disrupted by rearrangement. MED } 2 \text { I at } \\
\text { breakpoint may be required to displace histones to enable } \\
\text { heat-shock response }{ }^{14} \text {. }\end{array}$ & SOX5 & $\begin{array}{l}\text { SOX5, KRAS, } \\
\text { MED } 21\end{array}$ & SOX5, KRAS & SOX5 \\
\hline DGAPI 24 & $\begin{array}{l}\text { NRXNI, repressive histone marker at rearrangement } \\
\text { breakpoint, controls choice of NRXN splicing isoform. } \\
\text { Repressed by histone methyl-transferase } 15 \\
\end{array}$ & NRXNI & NRXNI & NRXNI & Not found \\
\hline DGAPI 27 & PAK3), compensates for PAKI which interacts with histone $\mathrm{H} 3$ & PAK3 & PAK3 & PAK3 & Not found \\
\hline DGAPI33 & $\begin{array}{l}6 q|3-q| 4.1 \text { deleted includes } H M G N 3 \text { chromatin binding } \\
\text { protein that stimulates acetylation }{ }^{16}\end{array}$ & $\begin{array}{l}\text { SMAPI, B3GAT2, } \\
\text { OGFRLI, RIMSI, } \\
\text { SLCI7A5, FILIPI, LCA5, } \\
\text { SENP6, etc (See Fig I) }\end{array}$ & $\begin{array}{l}\text { KHDCI, EEFIAI, } \\
\text { MYO6, } \\
\text { IRAKIBPI, } \\
\text { B3GAT2, etc. (see } \\
\text { Fig I) }\end{array}$ & $\begin{array}{l}\text { Collagen genes } \\
19 \mathrm{~A}, 12 \mathrm{~A}, \\
\text { COX7A2 }\end{array}$ & Col9A \\
\hline DGAPI39 & |3q|4.2 deleted Includes SETDB2 ${ }^{17}$ (See Fig. I) & $\begin{array}{l}\text { SUCLA2, ITM2B, } \\
\text { RCBTB2, CYSLTR2, } \\
\text { KPNA3 }\end{array}$ & $\begin{array}{l}\text { RBI, NUDTI5, } \\
\text { DLEUI,2, PHFII, } \\
\text { SETDB2, KCNRG }\end{array}$ & $\begin{array}{l}\text { ITM2B, CYSLTR2, } \\
\text { LPAR6, DLEU2 }\end{array}$ & DLeu2 \\
\hline DGAPI42 & $\begin{array}{l}\text { MBD5 Epigenetic regulator Histone acetylation disrupted by } \\
\text { rearrangement. }\end{array}$ & MBD5 & MBD5 & MBD5 & Not found \\
\hline
\end{tabular}


bioRxiv preprint doi: https://doi.org/10.1101/448845; this version posted October 22, 2018. The copyright holder for this preprint (which was not certified by peer review) is the author/funder, who has granted bioRxiv a license to display the preprint in perpetuity. It is made available under aCC-BY-ND 4.0 International license.

\begin{tabular}{|c|c|c|c|c|c|}
\hline DGAPI45 & $\begin{array}{l}\text { EFTUD2 [RNA splicing regulator in spliceosome] at } \\
\text { rearrangement breakpoint. Connects methylated histone to } \\
\text { RNA splicing }{ }^{18}\end{array}$ & EFTUD2 & EFTUD2 & EFTUD2 & EFTUD2 \\
\hline DGAPI47 & NALCN Disrupted at breakpoint & NALCN & NALCN & Not found & Not found \\
\hline DGAPI54 & Xq25 (Duplication) XIAP, STAG2 ${ }^{19}$ & XIAP, THOC2, GRIA3 & XIAP & SMAD5 & SMAD5 \\
\hline DGAPI55 & $\begin{array}{l}\text { EHMTI/GLP: Encodes a histone methyltransferase, an } \\
\text { epigenetic regulator. }\end{array}$ & EHMTI & EHMTI & EHMTI & EHMTI \\
\hline DGAPI57 & $\begin{array}{l}\text { FOXPI'PRMT5 recruitment to the FOXPI promoter } \\
\text { facilitates } H 3 R 2 \text { me } 2 \text { s, } S E T I \text { recruitment, } H 3 K 4 m e 3 \text {, and gene } \\
\text { expression" } 20 \text { Disrupted by rearrangement. }\end{array}$ & FOXPI & FOXPI & FOXPI & FOXPI \\
\hline DGAPI59 & $\begin{array}{l}\text { IOpI5.3-p|4 Deletion includes GATA3 See Fig. I. GATA3 } \\
\text { controls enhancer accessibility, recruits chromatin remodeler to } \\
\text { reprogram cells. }\end{array}$ & GATA3 & GATA3 & GATA3 & GATA3 \\
\hline DGAPI6I & $\begin{array}{l}\text { 4q34 (See Fig. I) HMGB2, a chromatin protein affecting } \\
\text { epigenetic status }\end{array}$ & AGA, SPCS3, TENM & $\begin{array}{l}\text { HMGB2, HPGD, } \\
\text { VEGFc ADAM29 }\end{array}$ & VEGFc, ADAM29 & HMGB2, VEGFc \\
\hline DGAPI64 & $\begin{array}{l}\text { NODALlactivin a targets KDM6B (epigenetic regulator of } \\
\text { neuronal plasticity) signaling in mouse brain. Rearrangement } \\
\text { also disrupts TETI (a methylation eraser (demethylase) }\end{array}$ & NODAL & NODAL & NODAL & NODAL \\
\hline DGAPI66 & SCNIA & SCNIA & SCNIA & Not found & Not found \\
\hline DGAPI69 & $\begin{array}{l}\text { NR2FI disrupted by rearrangement, Induces global chromatin } \\
\text { repression }\end{array}$ & $\mathrm{NR} 2 \mathrm{FI}$ & Not found & $\mathrm{NR} 2 \mathrm{FI}$ & $\mathrm{NR} 2 \mathrm{FI}$ \\
\hline DGAPI73 & IIpI4.2 FIBIN, BBOXI, SLC5AI2, ANO3 & ANO3, BBOXI & Mucin 15 & Not found & Not found \\
\hline DGAPI86 & NR5AI disrupted, participates in resetting pluripotency & NR5AI & NR5AI & NR5AI & Not found \\
\hline DGAPI89 & SOX5 is a histone demethylase & sox5 & SOX5 & SOX5 & SOX5 \\
\hline DGAPI90 & SMS Drives interactions among nucleosomes. & $\begin{array}{l}\text { Spermine synthetase } \\
\text { gene, spermine. }\end{array}$ & $\begin{array}{l}\text { Spermine } \\
\text { synthetase gene, } \\
\text { spermine. }\end{array}$ & $\begin{array}{l}\text { Spermine } \\
\text { synthetase gene, } \\
\text { spermine. }\end{array}$ & $\begin{array}{l}\text { Spermine } \\
\text { synthetase gene, } \\
\text { spermine. }\end{array}$ \\
\hline DGAPI93 & SPAST & SPAST & SPAST & SPAST & SPAST \\
\hline DGAPI99 & NOTCH2, disrupted at breakpoint by rearrangement. & $\mathrm{NOTCH} 2$ & $\mathrm{NOTCH} 2$ & $\mathrm{NOTCH} 2$ & $\mathrm{NOTCH} 2$ \\
\hline DGAP20I & $\begin{array}{l}\text { AUTS2 Disrupted at breakpoint by rearrangement. } \\
\text { Associated with chromatin structure }\end{array}$ & AUTS2 & AUTS2 & Not found & Not found \\
\hline DGAP202 & $\begin{array}{l}\text { KDM6A Histone di/tri demethylase disrupted at breakpoint } \\
\text { by rearrangement. }\end{array}$ & KDM6A & KDM6a & KDM6a & KDM6a \\
\hline DGAP2II & $\begin{array}{l}\text { SATB2 Disrupted at breakpoint by rearrangement. Epigenetic } \\
\text { functions, interacts with chromatin remodelers. }\end{array}$ & SATB2 & SATB2 & Not found & SATB2 \\
\hline DGAP2I 9 & $\begin{array}{l}\text { CUL3 Ubiquitin ligase recruited to regulate chromatin pattern } \\
\text { of lymphoid effector programs. Disrupted at breakpoint of } \\
\text { rearrangement. }\end{array}$ & CUL3 & CUL3 & CUL3 & CUL3 \\
\hline DGAP232 & $\begin{array}{l}\text { SNRPN-SNURF / SMN; PWCR; SM-D; sm-N; RT-LI; } \\
\text { HCERN3; SNRNP-N; Required for epigenetic imprinting. }\end{array}$ & SNRPN-SNURF & SNRPN-SNURF & Not found & SNRPN-SNURF \\
\hline DGAP235 & $\begin{array}{l}\text { MBD5 Epigenetic regulator histone acetylation disrupted at } \\
\text { breakpoint of rearrangement. }\end{array}$ & MBD5 & MBD5 & MBD5 & Not found \\
\hline DGAP239 & CHD7 Chromatin remodeler. & CHD7 & CHD7 & Not found & CHD7 \\
\hline DGAP244 & CTNND2 & CTNND2 & CTNND2 & Not found & CTNND2 \\
\hline DGAP278 & $\begin{array}{l}\text { SNRPN-SNURF / SMN; PWCR; SM-D; sm-N; RT-LI; } \\
\text { HCERN3; SNRNP-N; Required for epigenetic imprinting }\end{array}$ & SNRPN-SNURF & SNRPN-SNURF & Not found & SNRPN-SNURF \\
\hline DGAP30I & $\begin{array}{l}\text { MEF2C, Associated with disease histone hypermethylation } \\
22 . . \text { Disrupted by rearrangement }\end{array}$ & MEF2C & MEF2C & MEF2C & MEF2C \\
\hline
\end{tabular}


bioRxiv preprint doi: https://doi.org/10.1101/448845; this version posted October 22, 2018. The copyright holder for this preprint (which was not certified by peer review) is the author/funder, who has granted bioRxiv a license to display the preprint in perpetuity. It is made available under aCC-BY-ND 4.0 International license.

\begin{tabular}{|c|c|c|c|c|c|}
\hline DGAP3I 6 & $\begin{array}{l}\text { I8p I I.32-p I I.22 deletion: PHF2 I A PHF2 I A Encodes } \\
\text { BHC80, a component of a BRAF35 histone deacetylase } \\
\text { complex. }\end{array}$ & PHF2IA & PHF2IA & $\begin{array}{l}\text { YESI, MYOMI, } \\
\text { EPB4IL3, } \\
\text { ARHGAP28, } \\
\text { LAMAI, PTPRM, } \\
\text { MTCLI, TWSGI, } \\
\text { RALBPI, RAB3I }\end{array}$ & $\begin{array}{l}\text { SMCHDI, TGIFI, } \\
\text { LAMAI, PTPRM, } \\
\text { TWSGHI, }\end{array}$ \\
\hline DGAP3I7 & 6qI4.I TBXI8: IRAKIBPI; IBTK & $\begin{array}{l}\text { LCA5, ELOV4, HTRIB, } \\
\text { DOPEY }\end{array}$ & $\begin{array}{l}\text { IRAKIBPI,TBXI8 } \\
\text { IBTK NFKB }\end{array}$ & COX7A & Not found \\
\hline MGH7 & GRIN2B Reflects changes in methylation levels ${ }^{23}$ & GRIN2B & GRIN2B & Not found & Not found \\
\hline MGH8 & $\begin{array}{l}\text { CHD8, chromatin insulator blocks effects of nearby } \\
\text { enhancers. CHD8 interacts with the insulator binding protein } \\
\text { CTCF to insulate and epigenetically regulate }{ }^{24} \text {. }\end{array}$ & CHD8 & CHD8 & Not found & Not found \\
\hline MGH9 & $\begin{array}{l}\text { TCF4 regulated by histone deacetylases. Binding sites overlap } \\
\text { histone acetylation of enhancers }{ }^{25}\end{array}$ & TCF4 & TCF4 & TCF4 & TCF4 \\
\hline NIJ2 & $\begin{array}{l}\text { PHIP, linked to histone methylation }{ }^{26} \text { Disrupted at breakpoint } \\
\text { by rearrangement. }\end{array}$ & PHIP, MYO6 & PHIP, MYO6 & PHIP, MYO6 & PHIP, MYO6 \\
\hline NIJ5 & ILIRAPLI & ILIRAPLI & ILIRAPLI & Not found & Skeletal growth \\
\hline NIJ6 & KAT6B / MORF/ MYST4 Lysine acetyl transferase. & KAT6B & KAT6B & KAT6B & KAT6B \\
\hline $\mathrm{NIJ} / 4$ & NFIA, regulated by chromatin structure 27 & NFIA & NFIA & NFIA & NFIA \\
\hline $\mathrm{NIJ} 15, \mathrm{NIJ} 6$ & MYTIL & MYTIL & MYTIL & Not found & Not found \\
\hline ROC4 & CAMTAI & CAMTAI & CAMTAI & CAMTAI & CAMTAI \\
\hline ROCI7 & AUTS2 Associated with H3K4me3 and epigenetic control & AUTS2 & AUTS2 & Not found & Not found \\
\hline ROC23 & TCFI2 & TCFI2 & TCFI2 & TCFI2 & TCFI2 \\
\hline ROC43 & SOX5 is a histone demethylase & SOX5 & SOX5 & SOX5 & SOX5 \\
\hline ROC62 & SNRPN-SNURF Required for epigenetic imprinting & SNRPN-SNURF & SNRPN-SNURF & Not found & SNRPN-SNURF \\
\hline UTR7 & NFIX, controlled by methylation & NFIX & NFIX & NFIX & NFIX \\
\hline UTRI2 & DYRKIA, histone phosphorylation & DYRKIA & DYRKIA & DYRKIA & DYRKIA \\
\hline UTRI3 & $\begin{array}{l}\text { MBD5, Epigenetic regulator disrupted in topology associated } \\
\text { domain }\end{array}$ & MBD5 & MBD5 & MBD5 & Not found \\
\hline UTRI7 & $\begin{array}{l}\text { ZBTB20, binds to genes that control chromatin architecture } \\
\text { including MEF2c and SAT2b) }\end{array}$ & ZBTB20 & ZBTB20 & ZBTB20 & ZBTB20 \\
\hline UTR20 & FOXP2 & FOXP2 & FOXP2 & FOXP2 & FOXP2 \\
\hline UTR2I & NSDI lysine methylation & NSDI & NSDI & NSDI & NSDI \\
\hline UTR22 & $2 q 24.3$ SCN9A & SCN9A, TTC2IB, STK39 & NOSTRIN, CERS6 & $\begin{array}{l}\text { FIGN, XIRP2, } \\
\text { CERS6 }\end{array}$ & TTC2IB \\
\hline $\begin{array}{l}\text { Affected } \\
\text { member of } \\
\text { family I }\end{array}$ & $\begin{array}{l}\text { NCALD I exists in myristoyl and non myristoyl forms. } \\
\text { Histone deacetylase } I / \text { is a myristoyl hydrolase }{ }^{28} \text {. }\end{array}$ & NCALDI & NCALDI & Not found & NCALDI \\
\hline $\begin{array}{l}\text { Affected } \\
\text { member of } \\
\text { family I }\end{array}$ & $\begin{array}{l}\text { NPL - N-acetylneuraminate lyases regulate cellular sialic acid } \\
\text { concentrations by mediating its reversible conversion into N- } \\
\text { acetylmannosamine and pyruvate }\end{array}$ & NPL & NPL & NPL & NPL \\
\hline $\begin{array}{l}\text { Affected } \\
\text { member of } \\
\text { family I }\end{array}$ & $\begin{array}{l}\text { BCAR3. A candidate epigenetic mediator for increased adult } \\
\text { body mass index in socially disadvantaged females }{ }^{29}\end{array}$ & Not found & Not found & BCAR3 & BCAR3 \\
\hline $\begin{array}{l}\text { Affected } \\
\text { member of } \\
\text { family } 2\end{array}$ & $\begin{array}{l}\text { ZNF423 - epigenetic modifications associated with obesity }{ }^{30} \text {, } \\
\text { methylation marker for age prediction. }\end{array}$ & ZNF423 & ZNF423 & & ZNF423 \\
\hline $\begin{array}{l}\text { Affected } \\
\text { member of } \\
\text { family } 3\end{array}$ & $\begin{array}{l}\text { RAPIGDSI - RAPI GTP-GDP dissociation stimulator } I^{31} \text {. } \\
\text { Antagonizes some histones. }\end{array}$ & RAPIGDSI - RAPI & $\begin{array}{l}\text { RAPIGDSI - } \\
\text { RAPI }\end{array}$ & $\begin{array}{l}\text { RAPIGDSI - } \\
\text { RAPI }\end{array}$ & $\begin{array}{l}\text { RAPIGDSI - } \\
\text { RAPI }\end{array}$ \\
\hline
\end{tabular}




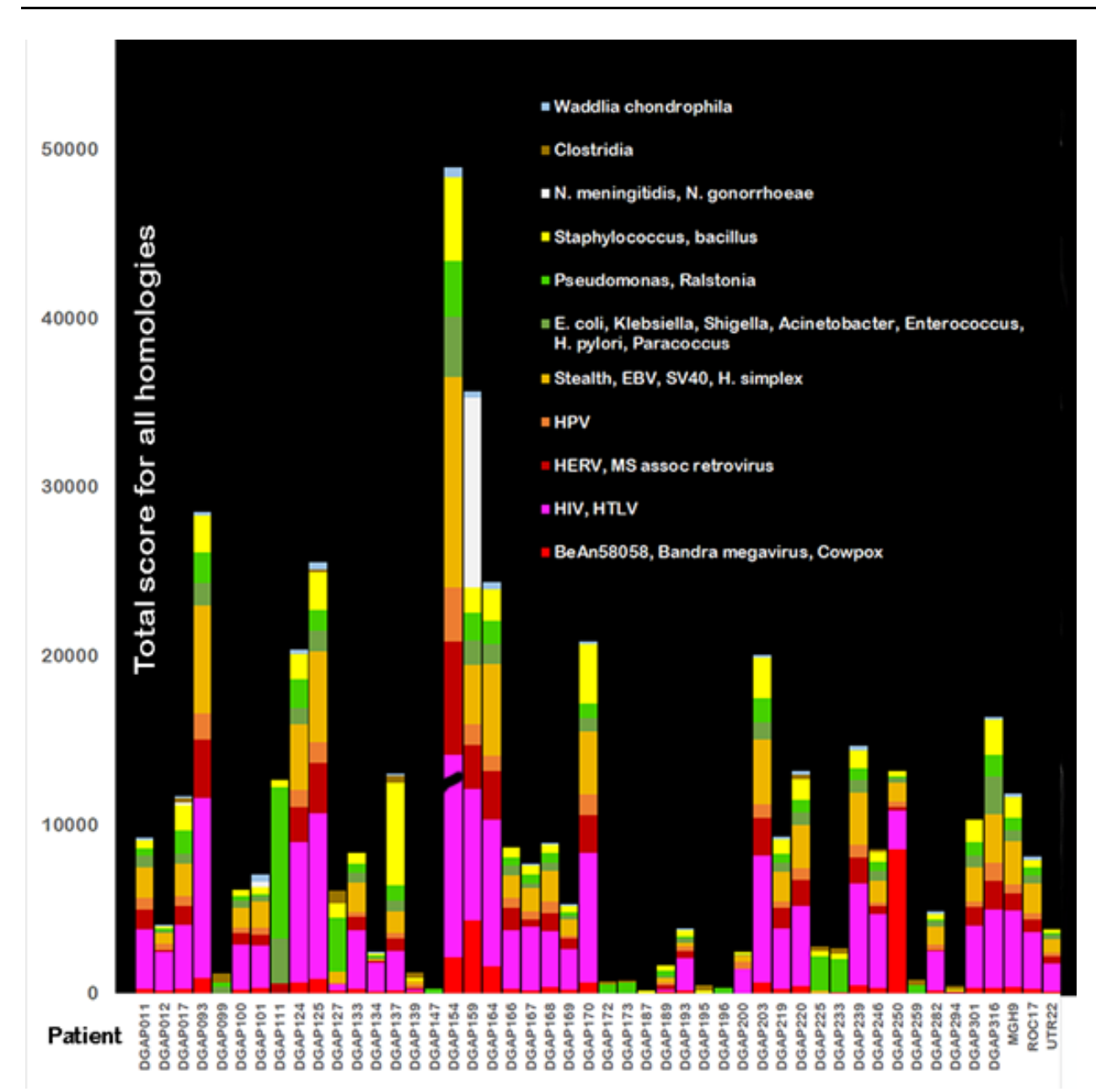

Fig. 3. Total scores for homologies among microorganisms and human chromosomal anomalies in 48 patients with neurodevelopmental disorders. The contributions from all homology scores for groupings or individual microorganisms that match the chromosomal anomaly in each patient are added together to form each bar in the graph. The microorganism homology scores are color-coded according to the type of individual microorganism. Of 1986 E values, the mean was 7.3e-13 [Range 8e-11 to 2E-168]. Some of the microorganisms found are not normally pathogenic but can become opportunistic pathogens if the immune system is impaired. Endogenous retroviral sequences may interfere with recombination or repair within a single cell. Total homology between DGAP154 and HIV/HTLV $(24,873)$ was truncated at 12,000 to prevent obscuring other data. 


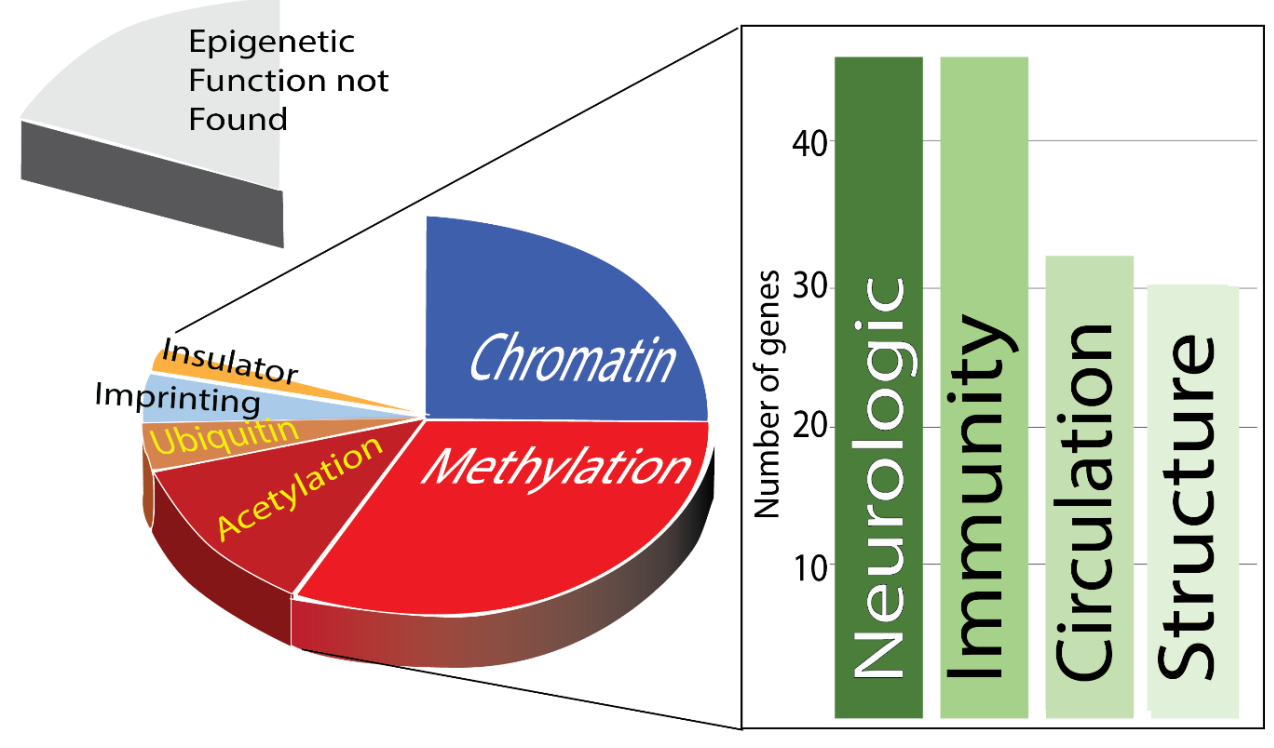

\section{Driver genes are epigenetic regulators of coordinated neurodevelopment functions}

Fig. 4. Driver genes truncated or deleted in congenital neurodevelopmental disorders are mainly epigenetic regulators or effectors. The pie chart shows the percentages of 46 driver genes with indicated epigenetic functions. Loss of these driver gene functions then impacts a group of functions that must be synchronized during the complex process of neurodevelopment. These are the same general functions lost in deleted gene clusters.

\section{Multiple infections identified by homology match signs and symptoms of neurodevelopmental disorders.}

In 48 patients I shown in Fig. 3, multiple infections are candidates to cause the signs and symptoms in each individual (Table 2). 8 patients have growth retardation or "short stature" which can be caused by exposure to many infections in the second or third trimester. The absence, delay, or impairment of speech were found in 20 of 48 patients '. Multiple infections can cause these problems. For instance, HIV-I causes white matter lesions associated with language impairments and impaired fetal growth. There are nearly 50 matches to HIV-I DNA in the chromosome anomalies of 35 patients. 


\section{Table 2. Recurrent infections found to have homology to chromosomal abnormalities in neurologic birth defects can cause developmental}

\section{defects.}

\section{Recurrent Infections matching DNA rearrangements in congenital neurologic disorders}

HIV-I, HIV-2

\section{CNS, physiologic and or teratogenic effects if known.}

\section{Numbers of Patients with chromosomal abnormalities with significant homologies to this infection} HIV-I causes white matter lesions associated with 600 matches in 36 patients mpaired fetal growth, premature delivery, chorioamnionitis, deciduitis, immunodeficiency. language impairments. HIV-I infects CNS by targeting microglial cells.
HPVI6 Part of a group of infections that coexist with other

viral infections, bacterial infections, and chemicals in 35 patients autism syndrome disorders ${ }^{32}$.
206 matches in 40 patients

May infect brain and interfere with normal nerve transmission. Causes meningitis, Brain abscess. Major hospital pathogens
Associated with neurologic impairments, hearing loss, ophthalmic problems.
425 matches in 39 patients

Opportunistic bacterial pathogen, associated with pneumonia and neonatal sepsis, especially in patients with compromised immunity on ventilator. Has some resemblance to other human pathogens including Borrelia, Bordetella, Burkholderia, and a "blood disease pathogen." Associated with neuropathy. Immune mediated disease of the nervous system affects spinal cord and 24 patients peripheral nerves. Fetal neural cells are highly susceptible to infection

BeAn 58058 is almost identical (97\%) to cotia virus which can infect human cells ${ }^{33}$. Represents a distinct branch of poxviruses ${ }^{34}$
50 matches in 36 patients
Klebsiella pneumoniae, e Neonatal pneumonia and sepsis.
coli
Neonatal pneumonia, trouble breathing virus Kilifi

Waddlia Chondrophila

Neisseria meningitidis, $\mathbf{N}$. gonorrhoeae
Recently discovered. Causes preterm birth, miscarriage, spontaneous abortion. Chlamydia like micro-organism. Survives in macrophages, multiplies in endometrial cells

Bacteria that can cause damage to human DNA. Premature birth, miscarriage, severe eye infection in infant. Antibodies to $\mathrm{N}$. gonorrhoeae impair outgrowth of neurites, and cross react with specific brain proteins.
7 patients: DGAP099, DGAPI27, DGAPI37, DGHAPI59, DGAPI67, DGAPI72, DGAP225

26 different patients

Patient DGAPI 59 shows 25 different homologies to $\mathrm{N}$. meningitidis. DGAPOI 7 and in DGAPIOI have homology to N. gonorrhoeae. 


$\begin{array}{ll}\text { Pseudomonas putida } & \begin{array}{l}\text { Gram-negative bacterium found in cases of acute } \\ \text { bacterial meningitis }{ }^{35} \text {. Reported in contaminated } \\ \text { water and heparinized flush solutions }{ }^{36}\end{array}\end{array}$

13 patients: DGAP0I2, DGAP93, DGAPI00, DGAPI25, DGAPI33, DGAPI34, DGAPI54, DGAPI59, DGAPI67, DGAPI69, DGAPI70, DGAP220, ROCI7

High catalase activity may disable immune defenses

Exiguobacterium depending on peroxide.

DGAPI27, DGAP225

Stealth viruses are frequent matches to chromosome anomalies with about 35 matching sequences. Stealth viruses are mostly derivatives of herpes viruses including cytomegalovirus (CMV) that emerge in immunosuppressed patients or have other mechanisms to avoid recognition by the immune system. Stealth virus I (Table 2) is Simian CMV (strain Colburn) African green monkey DMV, but closely related viruses with up to 95\% sequence identity have been isolated from human patients. First trimester CMV infection can cause severe cerebral abnormalities followed by neurologic symptoms ${ }^{37}$. CMV is also a common cause of congenital deafness and can cause visual abnormalities. 27 of the 48 neurodevelopmental patients had hearing loss or deafness. Herpes simplex virus is another stealth virus that directly infects the central nervous system. Herpes simplex can cause seizures (reported for 9 patients).

Patient DGAPI59 has the strongest homology to N. meningitidis (Fig. 3). N. meningitidis causes bacterial meningitis and is a known cause of neurodevelopmental defects. Signs and symptoms in patient DGAPI59 are consistent with residual effects of bacterial meningitis including hearing loss, developmental delay, speech failure and visual problems.

\section{DNA from microbes not classified as teratogens can also affect fetal development.}

Not only known teratogens, but almost all microbial DNA matching human chromosome anomalies in congenital neurologic disorders can have profound effects on a fetus or neonate (Table 2). Fig. 3 implies that any source of foreign DNA may contribute to developmental errors. Multiple matches represent homologies to human DNA among stretches of viral and bacterial DNA. Homologies found appear independent of whether microbes can insert into human DNA. HIV, HPVI6, HTLV-I, k. pneumoniae, ralstonia solanacearum, s. aureus, and stealth viruses are all found in at least 10 patients. 38 of 48 rearrangements include sequences that match one or more viruses, and 44 match bacterial sequences. In most chromosomal anomalies, multiple infections match a given anomalous 
DNA sequence. It is likely that most or all of these infections can interfere with neurodevelopment (Tables I-2). Fig. 3 includes endogenous retroviral sequences, mostly represent crippled infections that cannot travel between cells because they lack env genes needed to exit infected cells. However, HERV sequences are numerous and as retrotransposons, they can still interfere with recombination and DNA repair within their home cell.
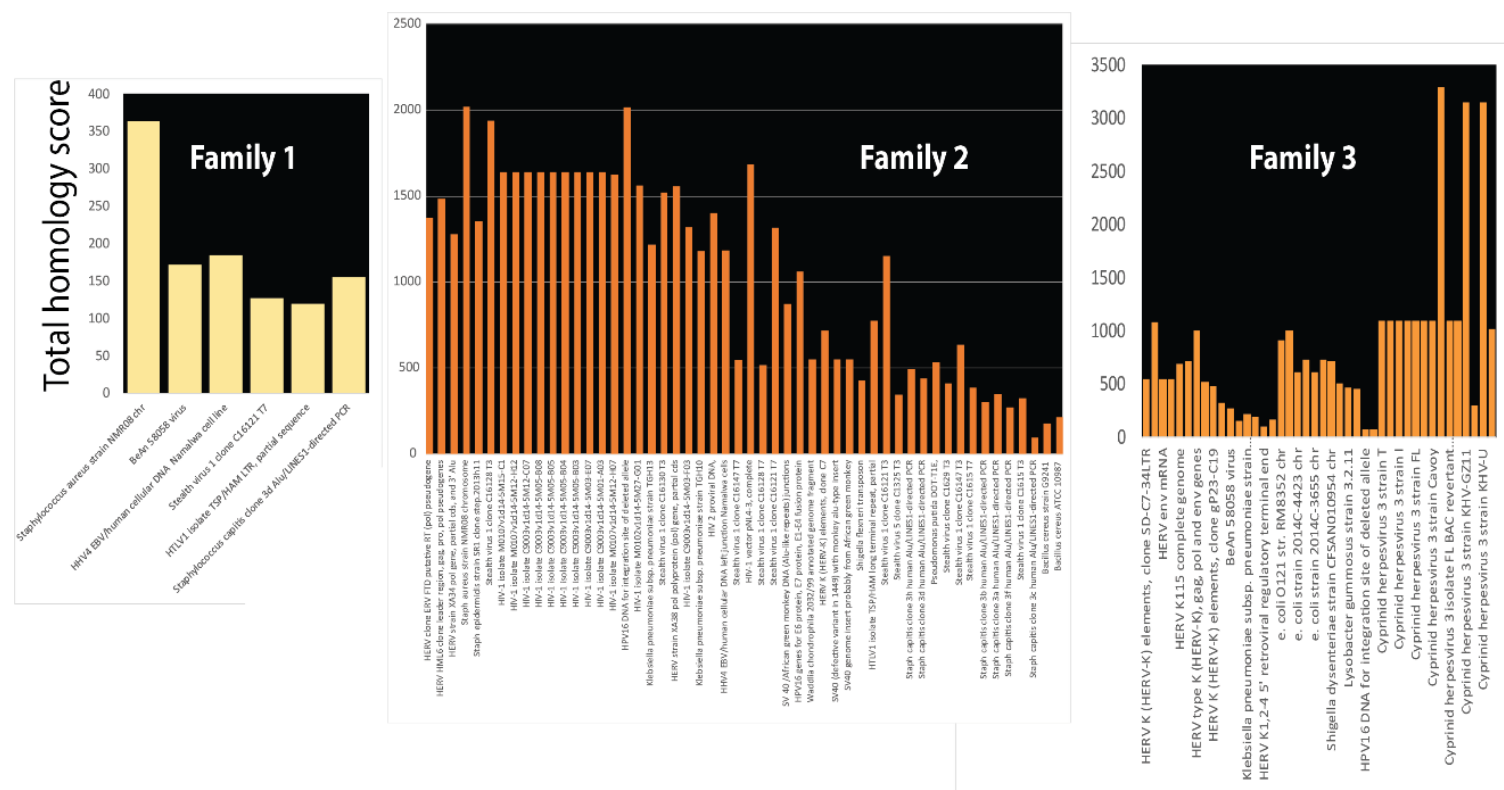

Fig. 5. Unbalanced deletions in three families with some affected members are homologous to microorganisms. Individuals affected by intellectual disability from families with apparently balanced translocations have other chromosome abnormalities including unbalanced deletions, insertions ${ }^{3}$. Chromosome deletions in each family are shown as homologous to bacterial and viral DNA, but insertions were also found to have similar homologies. Total homology scores for bacterial and viral homologies in each of the three affected patients are plotted.

\section{Deleted segments in familial chromosome anomalies point toward a general mechanism for infection as a cause of neurodevelopmental disorders.}

Effects of balanced translocations segregate only somewhat with the presence of neurodevelopmental disorders. These discrepancies are not extremely common but they emphasize the need to consider at least some genomes in three-dimensions ${ }^{38}$ and to consider cryptic anomalies. Genome sequencing of the entire family may be necessary ${ }^{3}$ because members of some families carry balanced chromosomal translocations but do not have signs and symptoms of neurodevelopmental disease. In three of four families with 
familial balanced chromosomal translocations, patient specific unbalanced deletions were also found but the results did not overlap any database of human reference genomes 3 .

Unbalanced deletions in the three families were strongly homologous to infections or other foreign DNAs (Fig. 5). In agreement with results in Table I, critical genes linked to epigenetic modifications were among those interrupted by cryptic rearrangements.
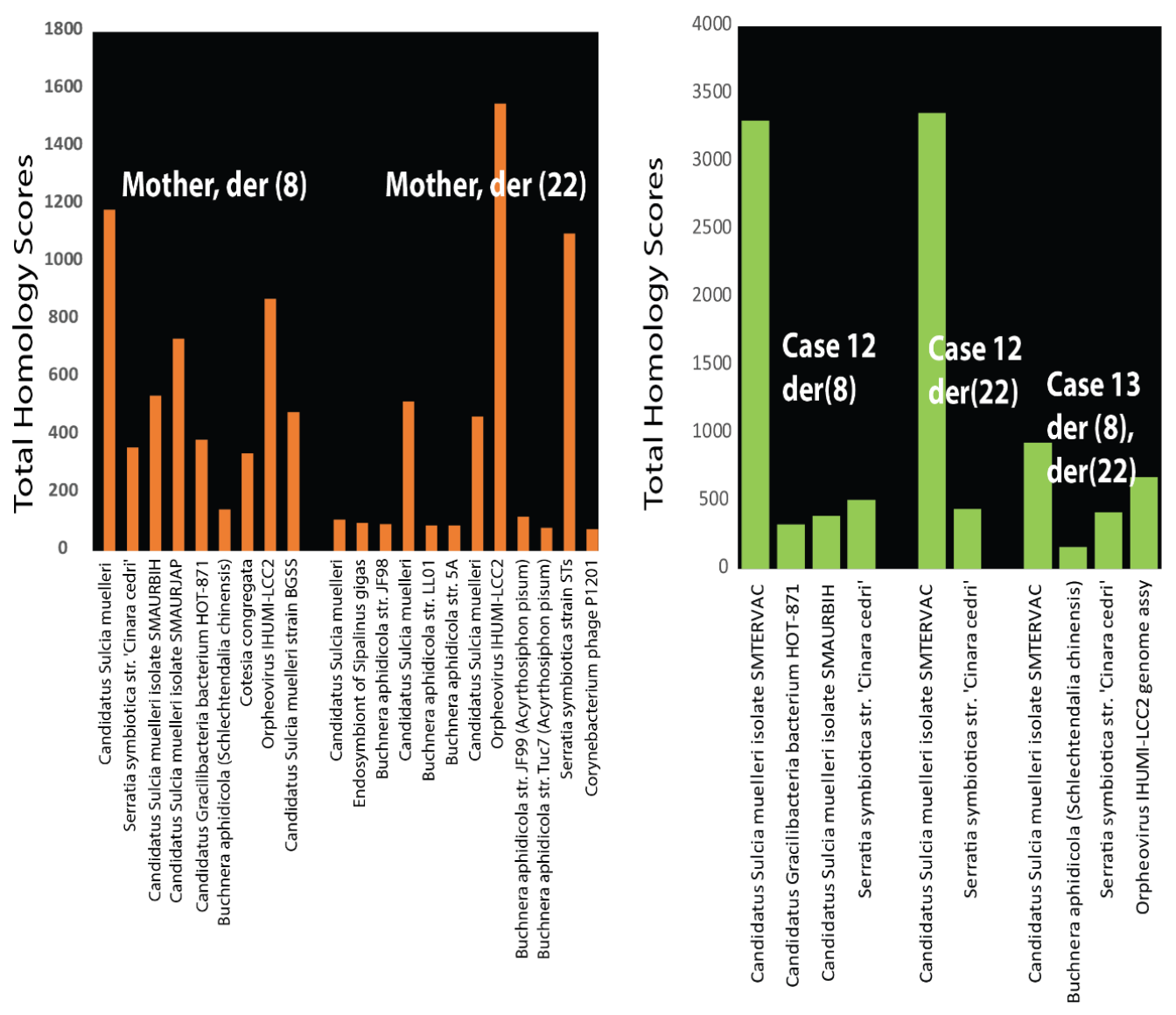

Fig. 6. Microbial homologies in cases from a maternal recurrent translocation. Parental translocation $\mathbf{t}(8 ; 22)$ in Family FHU13-027 from Mishra and colleagues ${ }^{2}$ is homologous to microorganisms as shown for der(8) (left) and for der(22) (right). The sequence is from a normal healthy mother who inherited from a female proband the balanced translocation $t(8 ; 22)$. More limited sets of micro-organisms are present in affected case 12 and case 13 (green bars) implying that DNA homologous to the other microorganisms has been lost.

Chromosome regions with microbial homologies in a recurrent translocation are only deleted in affected family members.

Recurrent de novo translocations between chromosomes II and 22 have so far only been detected during spermatogenesis and have been attributed to palindromic structures that induce genomic instability ${ }^{2}$. The recurrent breakpoint $t(8 ; 22)(q 24.13 ; q I I .2 I)^{2}$ was 
tested to determine whether palindromic effects might arise because microbial infection interferes with normal chromatin structures. Fig. 6 shows strong homology to bacterial and viral sequences in the recurrent breakpoint region. Sequences from an unaffected mother carry a balanced translocation rearrangement ${ }^{2}$ with homologies to more diverse microbes than are present in affected cases (Fig. 6). Parts of a chromosome segment with homologies to infection have been deleted in affected family members but not in unaffected ones.

\section{A model for infection interference in neurodevelopment.}

Infection DNA occurs in neurodevelopmental disorders that undergo autosomal dominant inheritance suggesting microbial DNA interferes with gamete generation in one parent. The mechanism proposed in Fig. 7 is based on significant homologies with microbial infections on multiple human chromosomes. Large amounts of foreign infection DNA present during human meiosis with its many double strand breaks and the most active period of recombination produce defective gametes. Errors in spermatogenesis underlie a prevalent and recurrent gene rearrangement that causes intellectual disability, and dysmorphism (Emanuel syndrome) ${ }^{2}$. In contrast, recombination in ova occurs in fetal life and then meiosis is arrested until puberty ${ }^{39}$.

The resemblance of foreign microbial DNA to host background DNA may be a major factor in selecting infection and in human ability to clear the infection. Only one rare defective gamete is modeled in Fig. 7 but the male generates four gametes during meiosis beginning at puberty. Only one gamete survives in the female because three polar bodies are generated. Both balanced and unbalanced translocations can give rise to chromosome anomalies such as deletions and insertions because infection DNA can insert itself (e.g. exogenous or endogenous retroviruses) or interfere with break repairs during meiosis. $A$ preexisting balanced chromosomal translocation in the family ${ }^{3}$ increases the chances of generating a defective gamete during meiosis. 

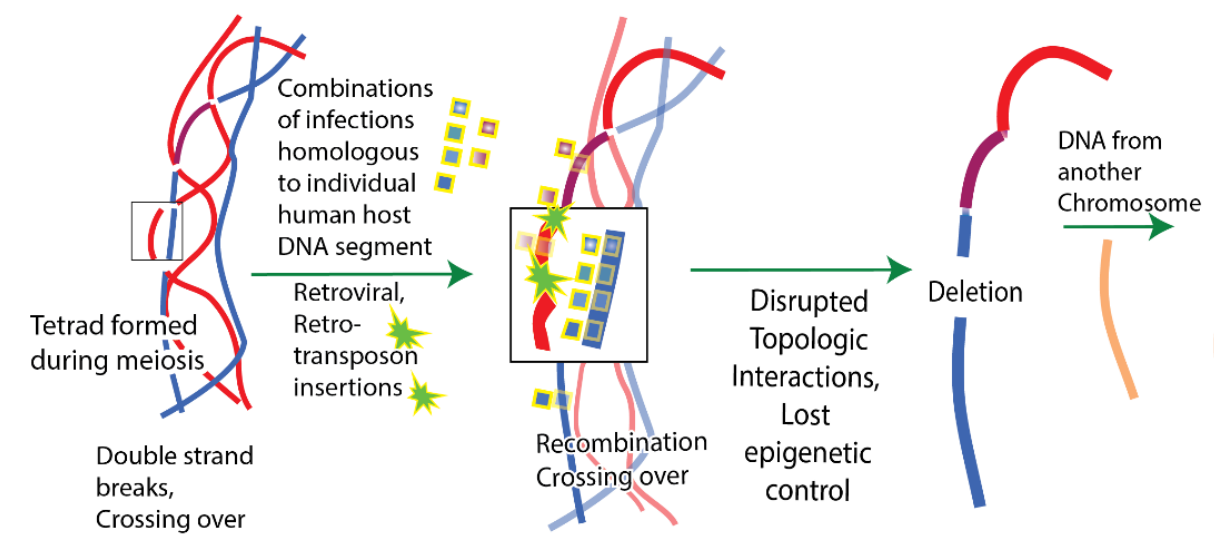

Gamete

with

deletion

Fig. 7. Model for interference with meiosis by DNA from infections leading to neurodevelopmental disorders. After duplication of parental chromosomes prior to generation of gametes, DNA from infections associates with strands of DNA in the many places including repetitive sequences of human DNA closely matching infection DNA. In addition, retroviruses and retrotransposons may integrate their DNA. Retroviral insertions are usually inactivated, but they can still interfere with normal processes such as reductive cell division, topological relationships among chromosomes, epigenetic regulation and high-fidelity break repair. Generally, interference from microorganisms may favor the illegitimate combinations due to palindromes reported by Mishra and co-workers 2. Hundreds of DNA breaks occur during meiosis and incorrect repair of these breaks is known to occur ', causing chromosome anomalies such as deletions (shown). Clustered genes responsible for linked functions and epigenetic regulation in neurodevelopment are lost or displaced. Other chromosome segments with microbial homology do not contain identified genes but may be essential control regions, insulators, or essential for chromatin structures. There are about one million Alu repeats alone in the human genome and many match sets of infections in individual neurodevelopment disorders. More private matches also occur. When combined with effects from other microorganisms this can cause severe disruption of base pairing in gamete generation.

\section{Tests for artifacts in matches to human-microbial DNA}

Genome rearrangements for patient data in Fig. 3 ' produced 1986 matches with $\mathrm{E}<=\mathrm{e}-10$ and a mean value of $83 \%$ identity to microbial sequences (range $66-100 \%$ ). About 190 Alu sequences resembled microbial sequences, supporting the idea that homologies among repetitive human sequences and microbes are real. Correspondence between microbial sequences and multiple human repetitive sequences increases possibilities that microbial sequences can interfere with essential human processes. Contamination of 
microbial DNA sequences by human Alu elements ${ }^{40}$, was tested by comparing about 450 Aluj, AluS and AluY sequences to all viruses and bacteria in the NCBI database. In contrast, LINE-I elements (NM_00I3306I2, NM_00I353293.I, NM_00I353279.I) had no significant homology to bacteria and viruses.

The 1986 microbial homologues to human DNA near chromosome breakpoints in neurodevelopmental disorders were composed of 126 different viral or bacterial sequences. 24 different strains of Neisseria meningitidis in patient DGAPI59 were 100\% identical to sequences within human genomic rearrangements. (Total scores 385-637, $E=8 e-13$ ). The $25^{\text {th }}$ strain was $98 \%$ identical. Clostridium specifically matched sections of human ATPases, and ATP synthases, mitochondrial G elongation factor, and heat shock protein hsp70 mRNA. A 1004 bp fragment of waddlia chondrophila occurred 32 times near neurodevelopmental breakpoints with full-length $89 \%$ homology to human calcyclin binding protein $(E=0.0)$. Waddlia chondrophila also had strong matches to human caspase recruitment. Another 55 of 126 viral / bacterial sequences were homologous to Alu sequences. Both non-Alu and Alu regions account for $90 \%$ (II 3 of 126$)$ of the sequences homologous to microbes and present near breakpoints in human neurodevelopmental disorders.

\section{Tests for DNA sequence artifacts.}

To further test the possibility that some versions of these microbial sequences were sequencing artifacts or contaminated by human genomes, microbial genomes represented in the Figures and other related microbial genomes were tested for homology to human genomes.

Homologies to human sequences were found across multiple strains of the same microorganism (Table 3). In other cases, homology to some human gene product was found but there was not sufficient data available to compare multiple versions of the same microorganism. In these cases, the human gene was tested against all bacteria, and viruses. There were hundreds of significant matches. The complete clostridium botulinum genome had significant homology to human enzyme CDKL2 (86\%) on chromosome 4. The region on chromosome 4: 579,587-75,632,298 spanned 52712 bp and was filled with over 50 Alu repeats, including multiple versions of AluS, AluY, and AluJ. Clostridium also had significant homology with long stretches on other chromosomes including chromosomes 2, 3, 10, 15, I, 5 with $74 \%$ homology over about 2853 bp E=0.0. Similarly, the full genome of waddlia chondrophila (2.I million bp) was homologous to multiple human genes (Table 3 ). 
Retroviral infections are known to insert their sequences in human DNA, destroy cells, or have other methods of infection and transmission, such as by inhibiting key protective mechanisms. HIV-I and other retroviral insertions matched congenital abnormalities in neurodevelopmental disorders. HIV-I isolate SC007 (GenBank: KY7I 3228.I) had $85 \%$ identity over 686 bases to human IgG2 lambda antibody and $82 \%$ homology to 412 bp of human DNA surrounding a rare Notl restriction site. To test for human sequence contaminants in these matching HIV sequences, Alu homologous regions of the HIV-I genome (bp 7300-9000) in 28 different HIV-I isolates were compared. All 28 HIV sequences matched the same region of human DNA, at up to $98 \%$ identity. The best match was to a LINCRNA on chrI I:74,929,289-74,929,4 I2. In contrast, only one zika virus sequence matched humans but 20 additional zika virus sequences did not, so zika virus was not considered further.

\section{Table 3. Independent evidence that microbial genomes have regions of}

\section{homology to human DNA as predicted by results.}

\begin{tabular}{|c|c|c|c|}
\hline Microbe & $\begin{array}{l}\text { Human chromosome } \\
\text { homologies }\end{array}$ & $\begin{array}{l}\text { Length of } \\
\text { homology } \\
\text { (bp) }\end{array}$ & $\begin{array}{l}\text { \%homology, E } \\
\text { value }\end{array}$ \\
\hline $\begin{array}{l}\text { N. gonorrhoeae strain } 1090 \\
\text { N. gonorrhoeae WHO-L } \\
\text { genome (GenBank: } \\
\text { LT591901.1) }\end{array}$ & 700 bp on Chromosomes $3,15, X$ and 3 & $233-345$ & $\begin{array}{l}100 \%, 5 e-89 \\
99-100 \%\end{array}$ \\
\hline N. gonorrhoeae strain 1090 & Clone image & 519 & $79 \%$ \\
\hline $\begin{array}{l}\text { S aureus } \\
\text { NC_007795.1 }\end{array}$ & ATPase & 1198 & $98 \%, E=0.0$ \\
\hline $\begin{array}{l}\text { Staphylococcus aureus } \\
\text { subsp. aureus }\end{array}$ & P143 mRNA & 642 & $70 \%, E=9 e-58$ \\
\hline S capitis & $\mathrm{ABC} 8$ & 218 & $71 \%, 5 e-15$ \\
\hline MRSA & Succinate CoA ligase, Chr13 & 769 & $67 \%$ \\
\hline Ralstonia solanacearum & $\begin{array}{l}\text { s-adenosyl-homocysteine hydrolase, } \\
\text { NM_001242673.1 Homo sapiens } \\
\text { adenosylhomocysteinase like } 1 \\
\text { (AHCYL1), transcript variant 2, mRNA } \\
\text { (>100 significant matches to other } \\
\text { microbial sequences) }\end{array}$ & 791 & $69 \% .2 e-73$ \\
\hline $\begin{array}{l}\text { Pseudomonas putida strain } \\
\text { IEC33019 complete genome } \\
\text { NZ_CP016634.1 vs strain T1E } \\
\text { (CP003734.1) }\end{array}$ & $\begin{array}{l}\text { Many hundreds of homologies e.g. } \\
\text { homo sapiens sequence around Not1 } \\
\text { site clone HSJ-DM24RS }\end{array}$ & 674 bp & $92 \%, E=0.0$ \\
\hline $\mathrm{C}$ botulinum & HSP70 member 9 & 1066 & $65 \% E=5 e-54$ \\
\hline C botulinum BrDura & Human cDNA & 692 & $83 \%, E=0.0$ \\
\hline $\begin{array}{l}\text { Waddlia chondrophila } \\
\text { (CP001928.1) whole genome } \\
2.1 \text { million bp }\end{array}$ & $\begin{array}{l}\text { Phosphoglycerate dehydrogenase, } \\
\text { fumarate hydratase } \\
\text { elongation factor alpha } \\
\text { hsp70 family member } 9 \\
\text { aldehyde dehydrogenase }\end{array}$ & $\begin{array}{l}734 \\
1034 \\
992 \\
1548 \\
1168 \\
\end{array}$ & $\begin{array}{l}66 \% E=9 e-71 \\
67 \% E=3 e-63 \\
71 \% E=1 e-112 \\
65 \% E=1 e-68 \\
64 \% E=1 e-30 \\
\end{array}$ \\
\hline
\end{tabular}




\begin{tabular}{|c|c|c|c|}
\hline $\begin{array}{l}67 \% \text { BeAn } 58058 \text { virus } \\
\text { NM_001165931.1 } 9 \\
\text { ribonucleotide reductase > } \\
100 \text { significant matches to } \\
\text { cotia virus (90\% homology), } \\
\text { Volepox, monkeypox, } \\
\text { cowpox, and vaccinia virus } \\
\text { e.g. } 675 / 939 \text { bp( } 72 \%) \text { E=4e- } \\
136\end{array}$ & $\begin{array}{l}\text { Ribonucleotide regulatory subunit } \\
\text { (Homo sapiens ribonucleotide reductase } \\
\text { regulatory subunit } \mathrm{M} 2(\mathrm{RRM} 2) \text {, } \\
\text { transcript variant } 1, \mathrm{mRNA})\end{array}$ & 870 & $68 \%, 8 e-69$ \\
\hline $\begin{array}{l}\text { Cowpox, KY369926.1 } \\
\text { Cowpox virus strain } \\
\text { Kostroma_2015, complete } \\
\text { genome }\end{array}$ & $\begin{array}{l}\text { At least } 100 \text { homologies. Homologies to } \\
\text { ribonucleotide reductase, } z \text {-protein } \\
\text { mRNA, transmembrane BAX inhibitor } \\
\text { motif, EF hand domain containing } \\
\text { EFHC2 }\end{array}$ & $\begin{array}{l}68-78 \% \\
\text { homology }\end{array}$ & $\begin{array}{l}2279 \text { bp at } 69 \% \\
\text { homology }(E=0.0)\end{array}$ \\
\hline HIV-1 28 different isolates & Alu homology bp7300 to 8000 & & $\begin{array}{l}\text { Up to } 98 \% \text { identity } \\
\text { for all } 28 \\
\text { sequences }\end{array}$ \\
\hline $\begin{array}{l}\text { HTLV1 J02029 vs } \\
\text { HTLV1/HAM Long terminal } \\
\text { repeat }\end{array}$ & $\begin{array}{l}\text { Homologous to hydroxysteroid } \\
\text { dehydrogenase like } 1 \text { variant, mRNA for } \\
\text { hGLI2 }\end{array}$ & $\begin{array}{l}97 \% \\
\text { homology }\end{array}$ & $\begin{array}{l}2162 \text { bp at } 97 \% \\
\text { homology }(E=0.0)\end{array}$ \\
\hline
\end{tabular}

\section{Discussion}

Long stretches of DNA in many infections match repetitive human DNA sequences which occur hundreds of thousands of times. Individual microorganisms also match nonrepetitive sequences. Human infections may be selected for and initially tolerated because of these matches. It is almost impossible to completely exclude the possibility of sequencing artifacts or contamination of microbial sequences with human sequences. However rather than reflecting widespread, wholesale error due to human DNA contamination in many laboratories over many years, microbial homologies more likely suggest that infection sequences have been selected because they are homologous to regions of human DNA. This may be a driving force behind the much slower evolution of Alu DNA.

Infections can cause mutations by interfering with the most active period of recombination which occurs during the generation of gametes, an ongoing process in males. Infections such as exogenous or endogenous retroviruses are known to insert into DNA hotspots ${ }^{38}$. Human DNA sequences that closely match infection DNA are proposed to generate chromosomal anomalies because similarities between microbial and human DNA interfere with meiosis (Fig. 7). Thus, the genetic background of an individual may be a key factor in determining the susceptibility to infection and to the effects of infection. At the genetic level, this suggests selective pressures for infections to develop and use genes that are similar to human genes and to silence or mutate genes that are immunogenic. Infection 
genomes evolve rapidly on transfer to a new host ${ }^{41}$. Infections with long stretches of DNA nearly identical to human DNA makes the infection more difficult to recognize as non-self. For example, there is no state of immunity to $N$. gonorrhoeae. Long stretches of $N$. gonorrhoeae DNA are almost identical to human DNA. Alu sequences and other repetitive elements are thought to underlie some diseases by interfering with correct homologous recombination ${ }^{42}$ or normal splicing. Infection DNA that is homologous to multiple, long stretches of human DNA may mask proper recombination or splice sites and encourage this abnormal behavior. Insertions of retroviral sequences are often epigenetically inactivated but can still interfere with meiosis and other normal processes (Fig. 7).

Neurons and cells in the immune system interact, sensing and adapting to their common environment. These interactions prevent multiple pathological changes in many disorders ${ }^{43}$. Many genes that are implicated in neurodevelopmental diseases, reflect the strong relationship between the immune system and the nervous system. It was always possible to find functions within the immune system for genes involved in neurodevelopmental disorders (Figs. I and 4). Damage to genes essential to prevent infection leads to more global developmental neurologic defects including intellectual disability. These microbial homologies include known teratogens. Analyses of mutations within clusters of genes deleted in neurodevelopmental disorders predict loss of braincirculatory barriers, facilitating infections. Damage to cellular genes essential for autophagy may lead to abnormal pruning of neural connections during postnatal development.

Aggregated gene damage accounts for immune, circulatory, and structural deficits that accompany neurologic deficits. Other gene losses listed in Table I and in deleted chromosome segments (Fig. I) account for deficits in cardiac function, cell barriers, bone structure, skull size, muscle tone and many other non-neurologic signs of neurodevelopmental disorders.

The arrangement of genes in clusters converging on the same biological process may simplify the regulation and coordination between neurons and other genes during neurodevelopment and neuroplasticity. Genes that are required for related functions, requiring coordinated regulation have been shown to be organized into individual topologically associated domains ${ }^{44}$. Functions that must be synchronized are grouped together on the same chromosome region and can be lost together by deletions (Fig. I) or by mutations of epigenetic controls (Table I). Neurons are intimately connected to chromatin 
architecture and epigenetic controls ${ }^{45}$. Homology to microbial infections anywhere in the cluster can then ruin complex coordinated neurological processes.

Microbial DNA sequences are unlikely to be contaminants or sequencing artifacts. They are all found connected to human DNA in disease chromosomes; multiple microbial sequences from different laboratories are all homologous to the same Alu sequence. Alu element-containing RNA polymerase II transcripts (AluRNAs) determine nucleolar structure and rRNA synthesis and may regulate nucleolar assembly as the cell cycle progresses and as the cell adapts to external signals ${ }^{46}$. HIV-I integration occurs with some preference near or within Alu repeats ${ }^{47}$. Alu sequences are largely inactive retrotransposons, but some humanmicrobial homologies detected may be due to insertions from Alu or other repetitive sequences. Neuronal progenitors may support de novo retrotransposition in response to the environment or maternal factors ${ }^{48}$.

Their variability and rarity make neurologic disorders difficult to study by conventional approaches. The techniques used here might eventually add to emerging disease prediction from medical imaging ${ }^{49}$ and help predict lifelong susceptibility to a given infection. However, the methods used await new developments enabling the ability to distinguish infection by one microorganism from multiple microorganisms.

\section{Conclusions}

I. DNAs in some congenital neurodevelopmental disorders closely matches multiple infections that extend over long linear stretches of human DNA and often involve repetitive human DNA sequences. The affected sequences are shown to exist as linear clusters of genes closely spaced in two dimensions.

2. Interference from infection can delete or damage human gene clusters and epigenetic regulators that coordinate neurodevelopment. This genomic interference accounts for immune, circulatory, and structural deficits that accompany neurologic deficits.

3. Neurodevelopmental disorders are proposed to begin when parental infections cause insertions or interfere with meiosis at both repetitive and unique human DNA sequences.

4. Congenital neurodevelopmental disorders are thus viewed as resulting from an assault on human DNA by microorganisms and an example of the selection of infecting microorganisms based on their similarity to host DNA. 


\begin{abstract}
Acknowledgments: This work is based on the outstanding DNA sequence information and publications from investigators listed in the references. These results emphasize the importance of their work. It is a pleasure to acknowledge the inspiration, challenge and stimulation provided by the Department of Biochemistry and Molecular Genetics and the College of Medicine at UIC.
\end{abstract}

Conflicts of Interest: The author declares no conflict of interest.

\title{
References
}

1. Redin C, Brand H, Collins RL, et al. The genomic landscape of balanced cytogenetic abnormalities associated with human congenital anomalies. Nat Genet. 2017;49(1):3645.

2. Mishra $D$, Kato $T$, Inagaki $H$, et al. Breakpoint analysis of the recurrent constitutional $\mathrm{t}(8 ; 22)(\mathrm{q} 24.13 ; \mathrm{q11.21})$ translocation. Mol Cytogenet. 2014;7:55.

3. Aristidou C, Koufaris C, Theodosiou A, et al. Accurate Breakpoint Mapping in Apparently Balanced Translocation Families with Discordant Phenotypes Using Whole Genome Mate-Pair Sequencing. PLoS One. 2017;12(1):e0169935.

4. Banik A, Kandilya D, Ramya S, Stunkel W, Chong YS, Dheen ST. Maternal Factors that Induce Epigenetic Changes Contribute to Neurological Disorders in Offspring. Genes (Basel). 2017;8(6).

5. Bhela S, Mulik S, Reddy PB, et al. Critical role of microRNA-155 in herpes simplex encephalitis. J Immunol. 2014;192(6):2734-2743.

6. Vrielynck N, Chambon A, Vezon D, et al. A DNA topoisomerase VI-like complex initiates meiotic recombination. Science. 2016;351(6276):939-943.

7. Zhang Z, Schwartz S, Wagner L, Miller W. A greedy algorithm for aligning DNA sequences. J Comput Biol. 2000;7(1-2):203-214.

8. Pearson WR. An introduction to sequence similarity ("homology") searching. Curr Protoc Bioinformatics. 2013; Chapter 3:Unit3 1.

9. Di Donato $M$, Bilancio $A, D$ 'Amato $L$, et al. Cross-talk between androgen receptor/filamin A and TrkA regulates neurite outgrowth in PC12 cells. Mol Biol Cell. 2015;26(15):28582872.

10. Aristidou C, Theodosiou A, Ketoni A, et al. Cryptic breakpoint identified by wholegenome mate-pair sequencing in a rare paternally inherited complex chromosomal rearrangement. Mol Cytogenet. 2018;11:34.

11. Wright CF, Fitzgerald TW, Jones WD, et al. Genetic diagnosis of developmental disorders in the DDD study: a scalable analysis of genome-wide research data. Lancet. 2015;385(9975):1305-1314.

12. Trazzi S, Fuchs C, Viggiano R, et al. HDAC4: a key factor underlying brain developmental alterations in CDKL5 disorder. Hum Mol Genet. 2016;25(18):3887-3907.

13. Hemming $S$, Cakouros D, Isenmann S, et al. EZH2 and KDM6A act as an epigenetic switch to regulate mesenchymal stem cell lineage specification. Stem Cells. 2014;32(3):802815.

14. Kremer SB, Kim S, Jeon JO, et al. Role of Mediator in regulating Pol II elongation and nucleosome displacement in Saccharomyces cerevisiae. Genetics. 2012;191(1):95-106.

15. Ding X, Liu S, Tian M, et al. Activity-induced histone modifications govern Neurexin-1 mRNA splicing and memory preservation. Nat Neurosci. 2017;20(5):690-699.

16. Barkess $G$, Postnikov $Y$, Campos CD, et al. The chromatin-binding protein HMGN3 stimulates histone acetylation and transcription across the Glyt1 gene. Biochem J. 2012;442(3):495-505. 
17. Parfett CL, Desaulniers D. A Tox21 Approach to Altered Epigenetic Landscapes: Assessing Epigenetic Toxicity Pathways Leading to Altered Gene Expression and Oncogenic Transformation In Vitro. Int J Mol Sci. 2017;18(6).

18. Guo R, Zheng L, Park JW, et al. BS69/ZMYND11 reads and connects histone H3.3 lysine 36 trimethylation-decorated chromatin to regulated pre-mRNA processing. Mol Cell. 2014;56(2):298-310.

19. Zhou Y, Alimohamadi S, Wang L, et al. A Loss of Function Screen of Epigenetic Modifiers and Splicing Factors during Early Stage of Cardiac Reprogramming. Stem Cells Int. 2018;2018:3814747.

20. Chiang K, Zielinska AE, Shaaban AM, et al. PRMT5 Is a Critical Regulator of Breast Cancer Stem Cell Function via Histone Methylation and FOXP1 Expression. Cell Rep. 2017;21(12):3498-3513.

21. Bronstein R, Kyle J, Abraham AB, Tsirka SE. Neurogenic to Gliogenic Fate Transition Perturbed by Loss of HMGB2. Front Mol Neurosci. 2017;10:153.

22. Mitchell AC, Javidfar B, Pothula V, et al. MEF2C transcription factor is associated with the genetic and epigenetic risk architecture of schizophrenia and improves cognition in mice. Mol Psychiatry. 2018;23(1):123-132.

23. Ryley Parrish R, Albertson AJ, Buckingham SC, et al. Status epilepticus triggers early and late alterations in brain-derived neurotrophic factor and NMDA glutamate receptor Grin2b DNA methylation levels in the hippocampus. Neuroscience. 2013;248:602-619.

24. Kunkel GR, Tracy JA, Jalufka FL, Lekven AC. CHD8short, a naturally-occurring truncated form of a chromatin remodeler lacking the helicase domain, is a potent transcriptional coregulator. Gene. 2018;641:303-309.

25. Forrest MP, Hill MJ, Kavanagh DH, Tansey KE, Waite AJ, Blake DJ. The Psychiatric Risk Gene Transcription Factor 4 (TCF4) Regulates Neurodevelopmental Pathways Associated With Schizophrenia, Autism, and Intellectual Disability. Schizophr Bull. 2017.

26. Morgan MAJ, Rickels RA, Collings CK, et al. A cryptic Tudor domain links BRWD2/PHIP to COMPASS-mediated histone H3K4 methylation. Genes Dev. 2017;31(19):2003-2014.

27. Glasgow SM, Carlson JC, Zhu W, et al. Glia-specific enhancers and chromatin structure regulate NFIA expression and glioma tumorigenesis. Nat Neurosci. 2017;20(11):15201528.

28. Moreno-Yruela C, Galleano I, Madsen AS, Olsen CA. Histone Deacetylase 11 Is an epsilon-N-Myristoyllysine Hydrolase. Cell Chem Biol. 2018;25(7):849-856 e848.

29. Chu SH, Loucks EB, Kelsey KT, et al. Sex-specific epigenetic mediators between early life social disadvantage and adulthood BMI. Epigenomics. 2018;10(6):707-722.

30. Lin X, Lim IY, Wu Y, et al. Developmental pathways to adiposity begin before birth and are influenced by genotype, prenatal environment and epigenome. BMC Med. 2017;15(1):50.

31. Chen M, Licon K, Otsuka R, Pillus L, Ideker T. Decoupling epigenetic and genetic effects through systematic analysis of gene position. Cell Rep. 2013;3(1):128-137.

32. Omura Y, Lu D, Jones MK, et al. Early Detection of Autism (ASD) by a Non-invasive Quick Measurement of Markedly Reduced Acetylcholine \& DHEA and Increased beta-Amyloid (1-42), Asbestos (Chrysotile), Titanium Dioxide, Al, Hg \& often Coexisting Virus Infections (CMV, HPV 16 and 18), Bacterial Infections etc. in the Brain and Corresponding Safe Individualized Effective Treatment. Acupunct Electrother Res. 2015;40(3):157-187.

33. Haller SL, Peng C, McFadden G, Rothenburg S. Poxviruses and the evolution of host range and virulence. Infect Genet Evol. 2014;21:15-40. 
34. Afonso PP, Silva PM, Schnellrath LC, et al. Biological characterization and nextgeneration genome sequencing of the unclassified Cotia virus SPAn232 (Poxviridae). J Virol. 2012;86(9):5039-5054.

35. Huang CR, Lien CY, Tsai WC, et al. The clinical characteristics of adult bacterial meningitis caused by non-Pseudomonas (Ps.) aeruginosa Pseudomonas species: A clinical comparison with Ps. aeruginosa meningitis. Kaohsiung J Med Sci. 2018;34(1):49-55.

36. Perz JF, Craig AS, Stratton CW, Bodner SJ, Phillips WE, Jr., Schaffner W. Pseudomonas putida septicemia in a special care nursery due to contaminated flush solutions prepared in a hospital pharmacy. J Clin Microbiol. 2005;43(10):5316-5318.

37. Oosterom N, Nijman J, Gunkel J, et al. Neuro-imaging findings in infants with congenital cytomegalovirus infection: relation to trimester of infection. Neonatology. 2015;107(4):289-296.

38. Babaei S, Akhtar W, de Jong J, Reinders M, de Ridder J. 3D hotspots of recurrent retroviral insertions reveal long-range interactions with cancer genes. Nat Commun. 2015;6:6381.

39. Hassold T, Hunt P. To err (meiotically) is human: the genesis of human aneuploidy. Nat Rev Genet. 2001;2(4):280-291.

40. Claverie JM, Makalowski W. Alu alert. Nature. 1994;371(6500):752.

41. Woolfit M, Iturbe-Ormaetxe I, Brownlie JC, et al. Genomic evolution of the pathogenic Wolbachia strain, wMelPop. Genome Biol Evol. 2013;5(11):2189-2204.

42. Nystrom-Lahti M, Kristo P, Nicolaides NC, et al. Founding mutations and Alu-mediated recombination in hereditary colon cancer. Nat Med. 1995;1(11):1203-1206.

43. Veiga-Fernandes H, Mucida D. Neuro-Immune Interactions at Barrier Surfaces. Cell. 2016;165(4):801-811.

44. Dixon JR, Gorkin DU, Ren B. Chromatin Domains: The Unit of Chromosome Organization. Mol Cell. 2016;62(5):668-680.

45. Fasolino M, Zhou Z. The Crucial Role of DNA Methylation and MeCP2 in Neuronal Function. Genes (Basel). 2017;8(5).

46. Caudron-Herger M, Pankert T, Rippe K. Regulation of nucleolus assembly by non-coding RNA polymerase II transcripts. Nucleus. 2016;7(3):308-318.

47. Cohn LB, Silva IT, Oliveira TY, et al. HIV-1 integration landscape during latent and active infection. Cell. 2015;160(3):420-432.

48. Muotri AR, Zhao C, Marchetto MC, Gage FH. Environmental influence on L1 retrotransposons in the adult hippocampus. Hippocampus. 2009;19(10):1002-1007.

49. Miller KL, Alfaro-Almagro F, Bangerter NK, et al. Multimodal population brain imaging in the UK Biobank prospective epidemiological study. Nat Neurosci. 2016;19(11):15231536. 